\title{
Implementation of antimicrobial stewardship policies in U.S. hospitals: findings from a national survey.
}

\author{
Monika Pogorzelska-Maziarz \\ Thomas Jefferson University, Jefferson School of Nursing \\ Carolyn T A Herzig \\ Columbia University, Mailman School of Public Health, School of Nursing, Center for Health Policy \\ Elaine L Larson \\ Columbia University, Mailman School of Public Health, School of Nursing, Center for Health Policy \\ E Yoko Furuya \\ Columbia University College of Physicians and Surgeons, NewYork-Presbyterian Hospital \\ Epllow this and additional works at: https://jdc.jefferson.edu/obgynfp \\ Eli NPerencevich

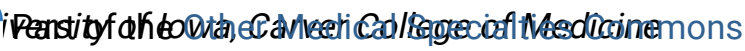 \\ Let us know how access to this document benefits you
}

See next page for additional authors

\section{Recommended Citation}

Pogorzelska-Maziarz, Monika; Herzig, Carolyn T A; Larson, Elaine L; Furuya, E Yoko; Perencevich, Eli N; and Stone, Patricia W, "Implementation of antimicrobial stewardship policies in U.S. hospitals: findings from a national survey." (2015). Department of Obstetrics and Gynecology Faculty Papers. Paper 33.

https://jdc.jefferson.edu/obgynfp/33

This Article is brought to you for free and open access by the Jefferson Digital Commons. The Jefferson Digital Commons is a service of Thomas Jefferson University's Center for Teaching and Learning (CTL). The Commons is a showcase for Jefferson books and journals, peer-reviewed scholarly publications, unique historical collections from the University archives, and teaching tools. The Jefferson Digital Commons allows researchers and interested readers anywhere in the world to learn about and keep up to date with Jefferson scholarship. This article has been accepted for inclusion in Department of Obstetrics and Gynecology Faculty Papers by an authorized administrator of the Jefferson Digital Commons. For more information, please contact:

JeffersonDigitalCommons@jefferson.edu. 
Authors

Monika Pogorzelska-Maziarz, Carolyn T A Herzig, Elaine L Larson, E Yoko Furuya, Eli N Perencevich, and Patricia W Stone 


\section{Infection Control \& Hospital Epidemiology}

http://journals.cambridge.org/lCE

Additional services for Infection Control \& Hospital Epidemiology:

Email alerts: $\underline{\text { Click here }}$

Subscriptions: $\underline{\text { Click here }}$

Commercial reprints: Click here

Terms of use : $\underline{\text { Click here }}$

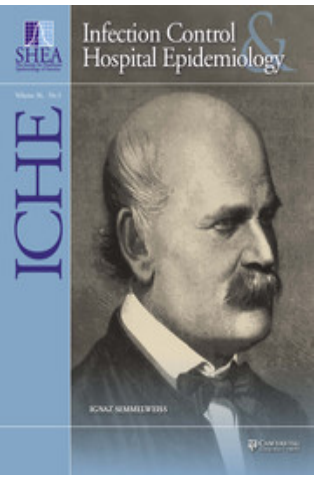

Implementation of Antimicrobial Stewardship Policies in U.S. Hospitals: Findings from a National Survey

Monika Pogorzelska-Maziarz, Carolyn T. A. Herzig, Elaine L. Larson, E. Yoko Furuya, Eli N. Perencevich and Patricia W. Stone

Infection Control \& Hospital Epidemiology / Volume 36 / Issue 03 / March 2015, pp 261 - 264

DOI: 10.1017/ice.2014.50, Published online: 09 January 2015

Link to this article: http://journals.cambridge.org/abstract S0899823X14000506

How to cite this article:

Monika Pogorzelska-Maziarz, Carolyn T. A. Herzig, Elaine L. Larson, E. Yoko Furuya, Eli N. Perencevich and Patricia W. Stone (2015). Implementation of Antimicrobial Stewardship Policies in U.S. Hospitals: Findings from a National Survey. Infection Control \& Hospital Epidemiology, 36, pp 261-264 doi:10.1017/ice.2014.50

Request Permissions : $\underline{\text { Click here }}$ 


\title{
Implementation of Antimicrobial Stewardship Policies in U.S. Hospitals: Findings from a National Survey
}

\author{
Monika Pogorzelska-Maziarz, PhD, MPH; ${ }^{1}$ Carolyn T. A. Herzig, MS; ${ }^{2}$ Elaine L. Larson, PhD, FAAN; ${ }^{3}$ \\ E. Yoko Furuya, MD, MS; ${ }^{4}$ Eli N. Perencevich, MD, MS; ${ }^{5}$ Patricia W. Stone, PhD, FAAN ${ }^{6}$
}

овјестіле. To describe the use of antimicrobial stewardship policies and to investigate factors associated with implementation in a national sample of acute care hospitals.

DESIGN. Cross-sectional survey.

PARTICIPANTs. Infection Control Directors from acute care hospitals participating in the National Healthcare Safety Network (NHSN).

methods. An online survey was conducted in the Fall of 2011. A subset of hospitals also provided access to their 2011 NHSN annual survey data.

RESULTS. Responses were received from 1,015 hospitals (30\% response rate). The majority of hospitals (64\%) reported the presence of a policy; use of antibiograms and antimicrobial restriction policies were most frequently utilized (83\% and $65 \%$, respectively). Respondents from larger, urban, teaching hospitals and those that are part of a system that shares resources were more likely to report a policy in place $(P<.01)$. Hospitals located in California were more likely to have policy in place than in hospitals located in other states $(P=.014)$

CONCLUSION. This study provides a snapshot of the implementation of antimicrobial stewardship policies in place in U.S. hospitals and suggests that statewide efforts in California are achieving their intended effect. Further research is needed to identify factors that foster the adoption of these policies.

Infect Control Hosp Epidemiol 2015;36(3):261-264

Healthcare-associated infections (HAIs), particularly those due to multidrug-resistant organisms, cause significant morbidity and mortality in acute care settings. ${ }^{1-3}$ Antimicrobial stewardship programs (ASPs) are one practice used to limit resistance and are especially crucial given the lack of new antimicrobials in development. ${ }^{4,5}$ In 2007, the Infectious Disease Society of America (IDSA) and the Society for Healthcare Epidemiology of America (SHEA) published a guideline ${ }^{6}$ for developing ASPs with the goal of improving patient outcomes while minimizing the unintended consequences of antimicrobial use. These programs have been shown to improve outcomes and reduce costs. ${ }^{6}$

Recognizing the importance of ASP, in a recent policy statement jointly published by IDSA, SHEA, and the Pediatric Infectious Disease Society, the authors recommended that ASPs be required through regulatory mechanisms, similar to Center for Medicare and Medicaid Services requirements, wherein all participating institutions would develop an ASP. ${ }^{7}$ Currently, California is the only state to mandate that all general acute-care hospitals develop a process for evaluating the judicious use of antimicrobials, although this mandate does not require a formal ASP (Senate Bill 739, Health and Safety Code $\$ \$ 1288$. 5-1288.9, 2006).

Given the growing evidence on the effectiveness of ASPs and increased interest in regulating implementation, the objective of this study was to describe the use of antimicrobial stewardship policies in a sample of National Healthcare Safety Network (NHSN) hospitals and to investigate factors associated with implementation.

\section{METHODS}

We conducted a national survey of infection control directors in acute care hospitals in the Fall of $2011 .^{8}$ A subset of hospitals

Affiliations: 1. Thomas Jefferson University, Jefferson School of Nursing, Philadelphia, Pennsylvania; 2. Columbia University, Mailman School of Public Health, School of Nursing, Center for Health Policy, New York, New York; 3. Columbia University, Mailman School of Public Health, School of Nursing, Center for Health Policy, New York, New York; 4. Columbia University College of Physicians \& Surgeons, NewYork-Presbyterian Hospital, New York, New York; 5. University of Iowa, Carver College of Medicine, Iowa City, VA, Iowa City, Iowa; 6. Columbia University, School of Nursing, Center for Health Policy, New York, New York.

Received July 24, 2014; accepted November 10, 2014; electronically published January 9, 2015

(c) 2015 by The Society for Healthcare Epidemiology of America. All rights reserved. 0899-823X/2015/3603-0004. DOI: 10.1017/ice.2014.50 
also provided access to their 2011 NHSN annual survey data. The survey process and data sources are described in detail elsewhere. ${ }^{8}$

Respondents were asked whether their hospital had a policy regarding antimicrobial stewardship and, if yes, to indicate the specific policies in place. The specific answer choices were as follows: antibiotic formulary restriction for selected agents, need for infectious disease (ID) or microbiology consult prior to prescribing antibiotics (ie, preauthorization), requiring an indication for antibiotics prescribed, use of automatic stop orders, providing clinicians with hospital or unit-based antibiograms, and prescriber audit and feedback. Additionally, the respondents were given the option to write in a response if it was not provided as one of the answer choices. Respondents were instructed to endorse all the policies that applied to their hospital. We specifically did not limit this question to asking only about policies included in a formal ASP because we were interested in capturing all stewardship activities in responding hospitals.

Data on infection control department staffing (ie, the presence of MD Hospital Epidemiologist (HE) and/or Infection Preventionist (IP) certification) and hospital characteristics (ie, location, bed size, setting, involvement in HAI initiatives) were also collected through the survey. Data on medical school affiliation, hospital type, and ownership status were available from the NHSN annual survey.

Descriptive statistics were calculated to describe the presence and types of policies. The $\chi^{2}$ and Fisher's exact tests were used to examine predictors of having a policy. Given the California mandate, presence of a policy and use of specific policies in California versus other states were compared using $\chi^{2}$ tests. Additionally, the analysis examining predictors of having a policy was repeated excluding California hospitals. Analyses were conducted in Stata, Version 11 (College Station, Texas). The study was approved by the Columbia University Medical Center's and RAND Corporation's Institutional Review Boards.

\section{RES ULTS}

Responses were received from 1,015 hospitals (ie, a response rate of $30 \%$ ). Additionally, NHSN annual survey data were available for 725 hospitals. The majority of respondents reported that their hospital had a policy regarding antimicrobial stewardship $(\mathrm{N}=652,64 \%)$. In these hospitals, the most frequently reported activities included providing clinicians with hospital- or unit-based antibiograms (83\%), antimicrobial restriction for select agents $(65 \%)$, and automatic stop orders (51\%). One-third of respondents reported policies requiring an ID or microbiology consult prior to prescribing antimicrobials $(35 \%)$ and prescriber audit and feedback $(34 \%)$. Fewer hospitals had a policy requiring that prescribers specify an indication for antimicrobial orders (23\%). Other types of policies reported (11\%) included pharmacy review and education.
The sample included 75 hospitals located in California, which were more likely to have a policy in place than hospitals located in other states $(77 \%$ vs $63 \%, P=.014)$. California hospitals reporting a policy were more likely to require specified indication for the antimicrobials prescribed (36\% vs $21 \%$, $P=.009$ ) and to have a policy for automatic stop orders $(62 \%$ vs $50 \%)$ than non-California hospitals; however, the latter did not reach statistical significance $(P=.075)$.

Characteristics of hospitals with and without a policy are presented in Table 1. Respondents from larger, urban, or teaching hospitals, or those taking part in an HAI initiative or that are part of a larger system that shares/pools IP resources were more likely to have a policy in place $(P<.01)$. In addition, respondents from hospitals with a full-time MD HE or with at least one IP certified in infection control were more likely to report a policy, as well as those with a neonatal or pediatric ICU $(P<.01)$. Hospital type, ownership, and geographic location were not statistically significant predictors of having a policy. Restricting the analysis to non-California hospitals did not change the results (data not shown).

\section{DISCUSSION}

These results come from the largest and most comprehensive survey of infection control departments in the United States and provide a snapshot of the antimicrobial stewardship policies currently utilized. We found that $66 \%$ of hospitals had a policy for antimicrobial stewardship; however, specific policy components differed among hospitals. A 2008 survey of SHEA members, 1 year after the publication of the guideline, ${ }^{6}$ found that $74 \%$ of hospitals had or were developing an ASP program, although only $48 \%$ reported that an ASP was currently in place. ${ }^{9}$ In addition, hospitals reported the implementation of antimicrobial stewardship policies even in the absence of a formal ASP. ${ }^{9}$ Similarly, in a 2009 survey of ID physicians participating in the IDSA Emerging Infections Network, $73 \%$ of respondents indicated that their hospital had or was planning an ASP.

Only one-third of hospitals reported that prescriber audit and feedback was instituted in their hospital even though this is one of the two core strategies recommended by the IDSA/ SHEA guideline ${ }^{6}$ and is an A-I level recommendation (evidence from $\geq 1$ properly randomized clinical trial and good evidence to support recommendation for use). Another core strategy recommended by the guideline is the use of preauthorization, which can lead to immediate and significant reduction in antimicrobial use (A-II level recommendation); however, preauthorization was reported by only one-third of hospitals. Both policies may be more difficult for hospitals to implement because they are resource-intensive and require dedicated staffing, ${ }^{10}$ which may be the reason for the infrequent implementation of these policies in some hospitals.

In our survey, hospitals located in California were more likely to report the presence of a policy than hospitals in other states (77\% vs 63\%). A high prevalence of ASPs in California was reported by Trivedi \& Rosenberg, with 50\% of California 
тав LE 1. Comparison of Hospitals With and Without Antimicrobial Stewardship/Restriction Policies in Place

\begin{tabular}{|c|c|c|c|}
\hline \multirow[b]{3}{*}{ Hospital Characteristics } & \multicolumn{3}{|c|}{ Antimicrobial Stewardship/Restriction Policy in Place } \\
\hline & Yes $(\mathrm{N}=652)$ & No $(\mathrm{N}=363)$ & \multirow[b]{2}{*}{$P^{\mathrm{a}}$} \\
\hline & $\mathrm{N}(\%)^{\mathrm{b}}$ & $\mathrm{N}(\%)^{\mathrm{b}}$ & \\
\hline \multicolumn{4}{|c|}{ Geographic location $(\mathrm{N}=1,015)$} \\
\hline Northeast & $136(21)$ & $53(15)$ & \multirow[t]{4}{*}{.090} \\
\hline Southeast & $225(35)$ & $141(39)$ & \\
\hline Midwest & $180(28)$ & $108(30)$ & \\
\hline West & $111(17)$ & $111(17)$ & \\
\hline \multicolumn{4}{|l|}{ Beds $(n=984)$} \\
\hline$\leq 200$ & $296(47)$ & $241(69)$ & \multirow[t]{3}{*}{$<.001$} \\
\hline $201-500$ & $260(41)$ & $86(25)$ & \\
\hline$>500$ & $79(12)$ & $22(6)$ & \\
\hline \multicolumn{4}{|l|}{ Setting $(n=1,009)$} \\
\hline Urban & $202(31)$ & $61(17)$ & \multirow[t]{3}{*}{$<.001$} \\
\hline Suburban & $234(36)$ & $100(28)$ & \\
\hline Rural & $213(33)$ & $199(55)$ & \\
\hline \multicolumn{4}{|c|}{ Hospital part of an HAI initiative $(\mathrm{N}=1,015)$} \\
\hline Yes & $452(69)$ & $220(61)$ & \multirow[t]{2}{*}{.005} \\
\hline No & $200(31)$ & $143(39)$ & \\
\hline \multicolumn{4}{|c|}{ Hospital part of a larger system that shares/pools IP resources $(n=1,002)$} \\
\hline Yes & $207(32)$ & $88(24)$ & \multirow[t]{2}{*}{.009} \\
\hline No & $435(68)$ & $272(76)$ & \\
\hline \multicolumn{4}{|c|}{ Full-time MD Hospital Epidemiologist $(\mathrm{n}=934)$} \\
\hline Yes & $198(33)$ & $78(23)$ & \multirow[t]{2}{*}{.001} \\
\hline No & $395(67)$ & $263(77)$ & \\
\hline \multicolumn{4}{|c|}{ Proportion of IP certified in infection control $(n=775)$} \\
\hline No IP certified & $162(32)$ & $146(53)$ & \multirow[t]{2}{*}{$<.001$} \\
\hline At least 1 IP certified & $338(68)$ & $129(47)$ & \\
\hline \multicolumn{4}{|l|}{ Ownership $(\mathrm{n}=725)$} \\
\hline Government & $24(5)$ & $24(9)$ & \multirow[t]{3}{*}{.098} \\
\hline Non-Profit & $357(77)$ & $192(74)$ & \\
\hline For Profit & $85(18)$ & $43(17)$ & \\
\hline \multicolumn{4}{|l|}{ Hospital type $(\mathrm{n}=725)$} \\
\hline General & $447(96)$ & $246(95)$ & \multirow[t]{3}{*}{.382} \\
\hline Children's & $9(2)$ & $9(3)$ & \\
\hline Specialty & $10(2)$ & $4(2)$ & \\
\hline \multicolumn{4}{|l|}{ Teaching status $(\mathrm{n}=725)$} \\
\hline Yes & $204(44)$ & $64(25)$ & \multirow[t]{2}{*}{$<.001$} \\
\hline No & $262(56)$ & $195(75)$ & \\
\hline \multicolumn{4}{|l|}{ Neonatal ICU $(\mathrm{N}=1,015)$} \\
\hline Yes & $211(32)$ & $74(20)$ & \multirow[t]{2}{*}{$<.001$} \\
\hline No & $441(68)$ & $289(80)$ & \\
\hline Pediatric ICU $(\mathrm{N}=1,015$ & & & \\
\hline Yes & $89(14)$ & $29(8)$ & .007 \\
\hline No & $563(86)$ & $334(92)$ & \\
\hline
\end{tabular}

NOTE. IP, infection preventionist; HAI, healthcare-associated infection; ICU, intensive care unit.

${ }^{\text {a }} P$-values provided for $\chi^{2}$ or Fisher's exact test as appropriate.

$\mathrm{b}_{\%}$ may not add up to $100 \%$ due to rounding.

hospitals reporting a current ASP, and 30\% reporting a planned ASP. ${ }^{11}$ Moreover, 22\% reported that the California mandate influenced initiation of their ASP. ${ }^{11}$ Given the higher prevalence of antimicrobial stewardship policies in our California sample than in the rest of the country, it seems that the statutory requirement played a role in the initiation of antimicrobial stewardship policies. These results also confirm the finding that many California hospitals were able to meet the statutory requirements with the institution of policies and perhaps without specifically instituting a formal ASP. ${ }^{7}$ 
Several predictors of an antimicrobial stewardship policy were identified, including greater bed size, participation in HAI initiatives, and pooling of IP resources. These factors may relate to resources available for infection prevention and the hospital's focus on HAI prevention. In a study of the prevalence of ASPs at children's hospitals, Newland et a ${ }^{12}$ identified solid organ transplantation, greater bed size, and patient days as being associated with having a program. In the survey of California hospitals, those without an ASP were more likely to be smaller and located in a rural setting. ${ }^{11}$ Additional research is needed on ways to implement ASP in hospitals with limited resources and outreach and education efforts may need to focus on these settings.

The results of this study are limited due to its cross-sectional nature. Given the low response rate, there is potential for limited generalizability and nonresponse bias. When compared to survey respondents, non-respondents tended to be from smaller facilities with fewer patient days; however, there were no differences in terms of medical school affiliation, ownership, and central-line-associated bloodstream infection rates. ${ }^{8}$ Because respondents may be among the more committed hospitals, it may be possible that ASPs are less common among non-respondents. Another limitation is that survey respondents were directors of infection control departments. Clinicians involved in ASPs are predominantly physicians and pharmacists and less frequently IPs; ${ }^{9}$ however, infection control directors should be aware of different ASP policies in place at their hospitals. Our survey was not specifically designed to measure other aspects of stewardship policies, such as the department in which the program was housed, dedicated resources, or specific end points monitored, nor did we collect detailed information on the specific components of policies under study. These data would provide a detailed picture of the intensity of ASP activities and should be the focus of future research. While many hospitals indicated they had a restriction policy in place, we have no data on the agents restricted and whether the policy is related to quality improvement or costcontainment. Additionally, we did not ask whether the antimicrobial stewardship policies were part of a formal ASP. Our aim was to capture all stewardship efforts and not only those that were part of a structured program. This makes it challenging to compare our data to those from studies examining aspects of formal ASPs.

This study provides a snapshot of the implementation of antimicrobial stewardship policies in place in U.S. hospitals and shows that variation exists in the types of policies in place. Statewide efforts in California seem to be having their intended effect of increasing the implementation of policies. Further research is needed to strengthen the evidence base on the effectiveness of these policies and to identify factors that foster their adoption.

\section{ACKNOWLEDGMENTS}

We thank all of the National Healthcare Safety Network hospitals for their participation and support.
Financial support: This work was supported by the National Institute of Nursing Research (R01NR010107). The content is solely the responsibility of the authors and does not necessarily represent the official views of the National Institute of Nursing Research.

Potential conflicts of interest: MPM has served as a consultant for Becton, Dickinson, and Company. All other authors report no potential conflict of interest.

Address correspondence to Monika Pogorzelska-Maziarz, PhD, MPH, Thomas Jefferson University, Jefferson School of Nursing, 130 South $9^{\text {th }}$ Street, Philadelphia, PA 19107 (Monika.Pogorzelska@jefferson.edu).

\section{REFERENCES}

1. Cosgrove SE. The relationship between antimicrobial resistance and patient outcomes: mortality, length of hospital stay, and health care costs. Clin Infect Dis 2006;15:S82-S89.

2. Maragakis LL, Perencevich EN, Cosgrove SE. Clinical and economic burden of antimicrobial resistance. Expert Rev Anti Infect Ther 2008;6:751-763.

3. Roberts RR, Hota B, Ahmad I, et al. Hospital and societal costs of antimicrobial-resistant infections in a Chicago teaching hospital: implications for antibiotic stewardship. Clin Infect Dis 2009;49:1175-1184.

4. Spellberg B, Blaser M, Guidos RJ, et al. Combating antimicrobial resistance: policy recommendations to save lives. Clin Infect Dis 2011;52:S397-S428.

5. Lautenbach E, Perencevich EN. Addressing the emergence and impact of multidrug-resistant Gram-negative organisms: a critical focus for the next decade. Infect Control Hosp Epidemiol 2014;35:333-335.

6. Dellit TH, Owens RC, McGowan JE Jr, et al. Infectious Diseases Society of America and the Society for Healthcare Epidemiology of America guidelines for developing an institutional program to enhance antimicrobial stewardship. Clin Infect Dis 2007;15:159-177.

7. Policy statement on antimicrobial stewardship by the Society for Healthcare Epidemiology of America (SHEA), the Infectious Diseases Society of America (IDSA), and the Pediatric Infectious Diseases Society (PIDS). Infect Control Hosp Epidemiol 2012;33:322-327.

8. Stone PW, Pogorzelska-Maziarz M, Herzig CT, et al. State of infection prevention in US hospitals enrolled in the National Health and Safety Network. Am J Infect Control 2014;42:94-99.

9. Pope SD, Dellit TH, Owens RC, et al. Results of survey on implementation of Infectious Diseases Society of America and Society for Healthcare Epidemiology of America guidelines for developing an institutional program to enhance antimicrobial stewardship. Infect Control Hosp Epidemiol 2009;30:97-98.

10. Johannsson B, Beekmann SE, Srinivasan A, et al. Improving antimicrobial stewardship: the evolution of programmatic strategies and barriers. Infect Control Hosp Epidemiol 2011;32: 367-374.

11. Trivedi KK, Rosenberg J. The state of antimicrobial stewardship programs in California. Infect Control Hosp Epidemiol 2013;34:379-384.

12. Newland JG, Gerber JS, Weissman SJ, et al. Prevalence and characteristics of antimicrobial stewardship programs at freestanding children's hospitals in the United States. Infect Control Hosp Epidemiol 2014;35:265-271. 